\title{
BRIDGE INFORMATION MODELLING (BrIM) AND MODEL UTILIZATION AT WORKSITES IN FINLAND
}

\author{
Teemu Kivimäki \\ University of Oulu, Espoo, Finland \\ teemu.kivimaki@oulu.fi \\ Rauno Heikkilä \\ University of Oulu, Oulu, Finland \\ rauno.heikkila@oulu.fi
}

\begin{abstract}
The paper introduces and discusses bridge engineering, design and construction $R \& D$ results in a Finnish bridge cluster consortium (5D-Bridge). Development of national bridge information modelling guideline in Finland is introduced, as well as latest developments in 3D modelling in practice. A library of frequently used bridge components was developed to the use of the Finnish bridge cluster. Also the latest developments in integrating the information model with surveying and machine control is discussed. Results vary from success utilizing new tools to model concrete bridges and rebars in Tekla Structures and relative success through iteration regarding bridge blueprint production in actual bridge modelling and construction project, and the relative failures of creating and maintaining a national custom bridge components library for different CAD softwares. Machine control applications for bridge construction, such as excavating the foundations and piling are still tested mostly in limited pilots or simulations and waiting to be actually used in real bridge construction sites. Overall, the transition to using 3D information models for bridge construction projects is clearly inevitable as more and more bridge projects are being designed via information modelling.
\end{abstract}

\section{KEYWORDS: 3d, bridge, information, modelling}

\section{INTRODUCTION}

\subsection{Background}

Most of bridge design work is still being done using 2D and drawing based working principle. 3D modelling is, however, coming more and more into bridge design too.

In Finland, there is a consortium of bridge construction related companies called " $5 \mathrm{D}$-Bridge consortium". The consortium has board meetings every two or three months to discuss and share newest R\&D advancements in the bridge construction cluster. A total of 20+ organizations, including practically all the major players in Finnish bridge cluster, general contractors, design consultants, software manufacturers and importers and bridge administration, are involved in the consortium. 
The research center of construction technology of University of Oulu is acting as an organizer and secretary in the consortium that has been running since 2002, including the projects 5DBridge 1 and 2, mainly with Finnish Road Administration funding.

Previously we have published several conference papers on bridge automation, for example Connecting 3-D Concrete Bridge Design to 3-D Site Measurements. (Heikkilä et al., 2003), On the Economy and Benefits of 3-D Design Method in Bridge Engineering (Heikkilä et al., 2005) and Integrating 5D Product Modelling to On-site 3D Surveying of Bridges (Kivimäki and Heikkilä, 2009).

\subsection{Objectives}

The objectives of 5D-Bridge 1 and 2 projects were to develop the 3D-process and 3D-design of bridges in Finland, a research started in the "Intelligent bridge" project. Objectives of general contractors were to change the bridge construction process so that it enables and facilitates the flow of information between the different parties involved in a bridge construction process and to reduce waste of resources. The objectives of bridge design consultants were to improve the efficiency of bridge design via utilization of 3D design softwares and to develop new services for domestic and international bridge design. Software companies objectives were to develop their products to better suit the needs of 3D bridge modelling, and better integration to road design software and construction site measurements and surveying.

The objective of Bridge Finland subproject was to develop national bridge information modelling guidelines so that the work methods and models produced would be more uniform, and on the other hand still try to stay as neutral as possible to allow fast development of the field and to not block competition and introduction of new innovative methods of utilizing and producing the models.

The objective of Custom Components subproject was to produce a library of frequently used components for the use of the Finnish bridge cluster.

\section{METHOD}

\subsection{Development of National Guidelines for Bridge Information Modeling}

National bridge information modelling guidelines were ordered by the Finnish road administration to set national standards of producing and utilizing the information models. University of Oulu acted as a planner and organizer for the project. Classic and 3D bridge design expertise was commissioned from a large Finnish design consultant company AInsinöörit Ltd. The subproject is scheduled to last 11 months, ending in February 2010. 


\subsection{Applying and testing of 3D modelling in Bridge Design}

Tekla Structures and Solidworks have mainly been used in Finland for 3D modelling of bridges. AutoCAD Revit and MicroStation have been evaluated.

Tekla has developed several additional features and modelling processes of Tekla Structures. Technical Tekla Structures 3D bridge information modelling guidelines for Finland have been created. To date, several Finnish design consultant offices have applied Tekla Structures to bridge design pilot projects. Blueprint production tools and integration with construction site management was developed and tested. One of these bridge projects was the Crusellibridge project, where modelling and model utilization was ordered by Helsinki city bridge and road administration.

\subsection{Development of bridge components library}

A library of frequently used dynamic bridge components was produced under the 5D-Bridge consortium, so that they would not have to be modelled again for each new bridge model. This work was planned to be done together by all the design consultant offices in the consortium by listing the needed components and dividing the work between the consultants. Every office would then provide the consortium a portion of the library and University of Oulu would gather them together and distribute the library to the whole Finnish bridge cluster.

\subsection{Development of integration between 3D modelling and surveying}

Bridge information model integration to surveying is a key issue considering model utilization and one of the most promising new ways for utilizing the model at worksites. New ways of integrating models to surveying were developed by Tekla and Trimble, based on previous work by Terrasolid Ltd and University of Oulu to connect design software directly to total station via serial port (Kivimäki and Heikkilä, 2009).

\subsection{Development of integration between 3D modelling and machine control}

One field of automation that is currently being commercially used is model utilization for machine control. Either for excavators or piling machines, several GPS based solutions from different vendors exist to position the machine and utilize models to help increase productivity. Previously, machine control has not been integrated with 3D modelling of bridges, but several possible ways of utilizing machine control as related to bridges have surfaced in the 5D-Bridge consortium.

\section{RESULTS}

\subsection{Finnish General Guidelines for Bridge Information Modelling}

The current draft of the guidelines contains following chapters:

- Description of modelling, model detail levels and model utilization in each of the design phases of a bridge. The phases are preliminary design, general design, bridge design, construction design, and renovation planning. 
- Information model contents, technical guidelines discussion, such as coordinate systems, numbering of parts and model detail accuracy levels. Also description on how to report the status of a model and discussion about the as-built model.

- Design blueprints and how the 3d modelling process affects them.

- Quality control, how it should be done by the design office and what materials will be needed by the public administration to check the plans.

- Model utilization at work sites.

- Model handovers, what are the legal points related to handing over the models to the different parties in a bridge construction project.

Also a form containing the key issues that need to be agreed between the buyer of the information model (usually Finnish road administration) and the designer was developed. The form contains general information about the bridge project, list of parties involved, what starting information is available (laser scanned terrain models etc.), description of the details that are not yet accurately added to the model in each design phase, issues regarding model handovers to third parties, and what information will the as-built model contain, will as-built measurements and other information be inserted into the model.

\subsection{D Modeling of Bridges}

At the moment the only CAD used for 3D bridge information modelling in Finland is Tekla Structures. Tekla Structures offers a reasonable way of modelling the rebarring for concrete bridges, which gives it an advantage over competitor, which at the moment don't have as sophisticated rebar tools. Other features, such as ability to easily create and modify the terrain model around the bridge are in favour of SolidWork CAD. A new player in the Finnish 3D bridge design field is AutoCAD with its Revit software. Several bridges have been modelled in Estonia using Revit. However Revit still also lacks the special solutions needed for effective rebar modelling.

Tekla has developed a proto tool for importing road geometry from road design software and generating the bridge deck using a predefined cross section accord to the road geometry. This is currently the only way of making a bridge curved relative to both $\mathrm{x}$ - and $\mathrm{y}$-axis. The tool generates the bridge deck in "slices" of elements, causing some unideality to the bridge model. In the newest versions of Tekla Structures it is possible to create blueprints so that the slide lines don't show up in the drawing and make it look messy, as it was the case in prior versions. In figure 1, the Cruselli-bridge is shown, with the slice lines visible on the bridge deck. 


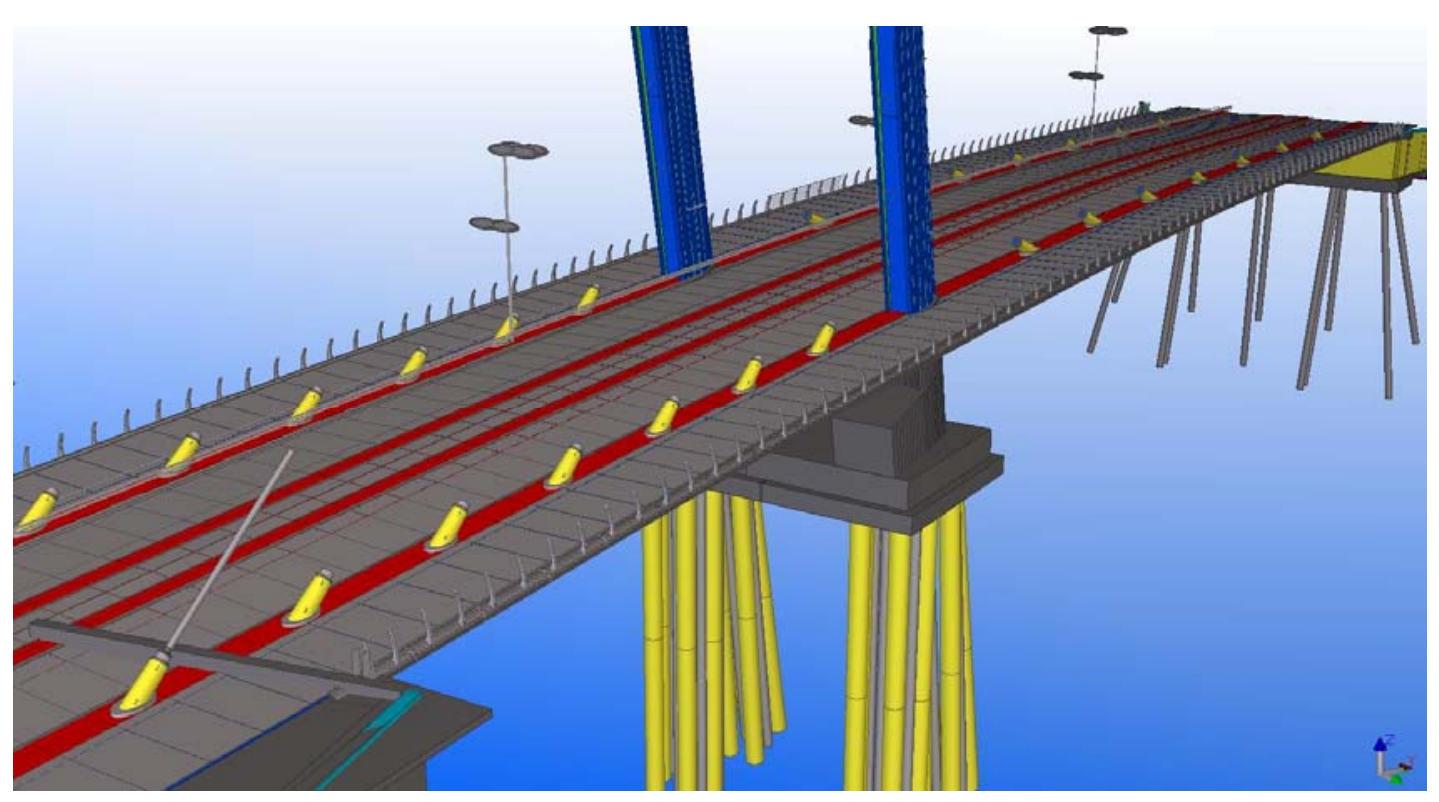

Figure 1. Cruselli Bridge, Finland (WSP Finland Oy).

\subsection{Custom Components project results}

A number of components with some dynamic functionality, such as length, were developed for Tekla Structures and SolidWorks CAD softwares. The components include for example railings and lighting poles. In figure 2, a custom component of a concrete railing modelled for Tekla Structures is shown. However, many of the components produced were working poorly, and almost none of them had a quality necessary for anyone else than the developer him/herself to be able to use them cost effectively. Because of this, only the steel railing pole component (figure 3) has been used in an actual bridge design project.

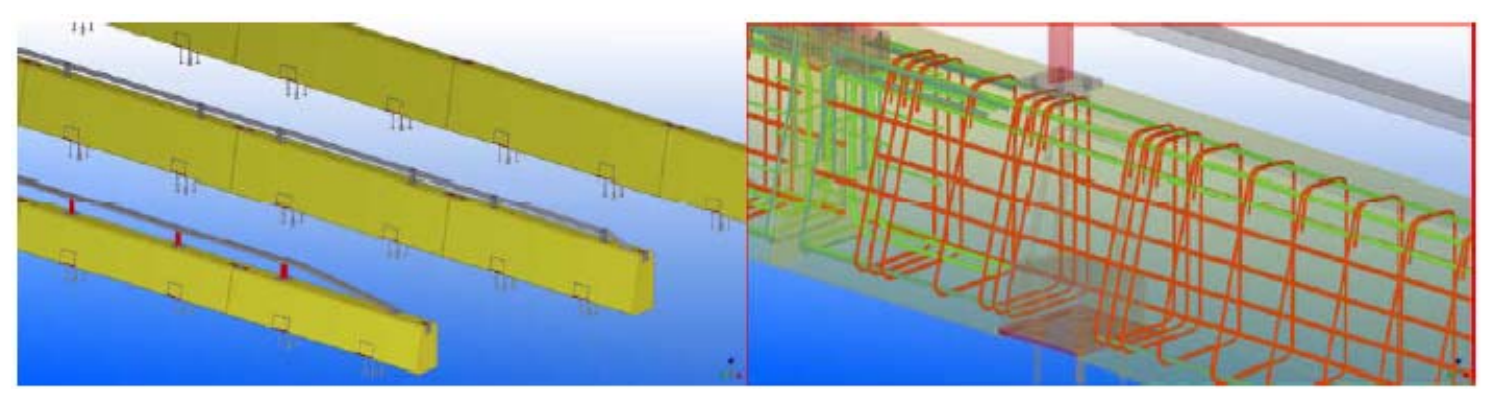

Figure 2. Example of a Tekla Structures custom component concrete railings with rebarring. 


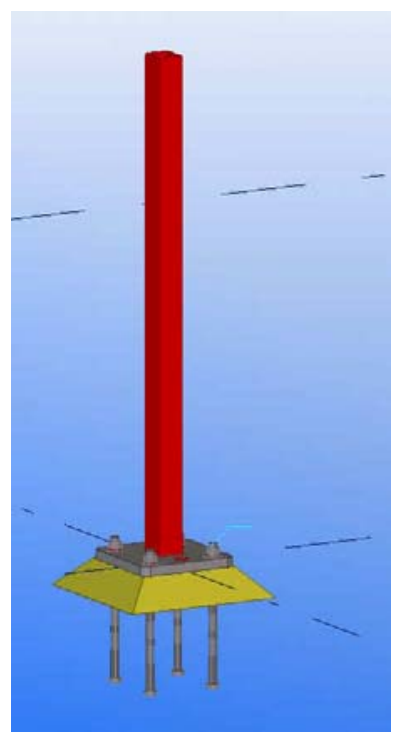

Figure 3. Tekla Structures steel railing pole custom component.

Also, a whole dynamic bridge type defined by the Finnish road administration was modelled by one of the consultants. The component has about 50 different parameters defining the bridge dimensions. Some 5\% of new bridges built in Finland are of this type. This component has not yet been tested in a real bridge project, but plans to do so are in motion.

\subsection{Integration of Product Model and Surveying}

As total station memory and computing power capabilities are increasing, the focus of bridge information model integration to surveying is now switching to uploading the whole model to the total station control unit memory as opposed to using Tekla Structures or other CAD addon to send commands to the total station via serial port.

Surveying can then be done using the total station control unit's user interface to select and measure points. In Tekla Structures, the model can be prepared for surveying by adding custom measurement indicator point to the model. These points, in addition to all other features of the model, are then visible on the total station UI and can be selected and easily measured by the surveyor. As-built information is gathered on the total station control unit directly on the information model. The model can then be transferred back to Tekla Structures for further revisioning by the designer or storage as an as-built model. In figure 4, a diagram displaying bridge information model and surveying integration using Tekla Structures and Trimble LM80 is shown. 


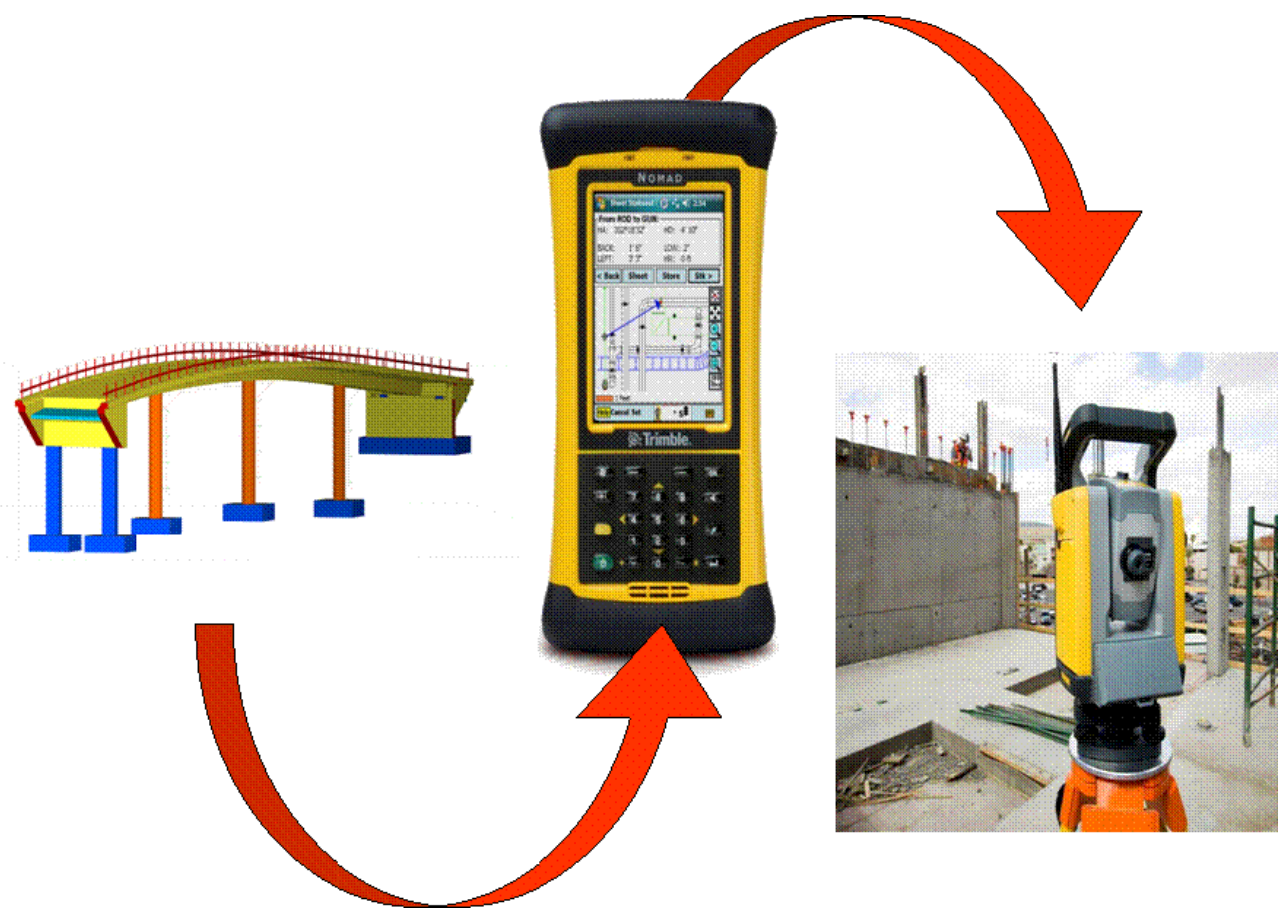

Figure 4. Tekla Structures and Trimble LM80 Integration.

\subsection{Integration of Product Model and Machine Control}

A possibility to automatically generate excavator machine control terrain models from a bridge information model was studied in Jyri Leppänen's bachelor thesis. In the thesis, two programs were developed. One to automatically create the terrain model based on the selected foundation elements, and another to create LandXML -format transfer file to be inserted in to the machine control system. Figure 5 shows images of foundations created with the program.

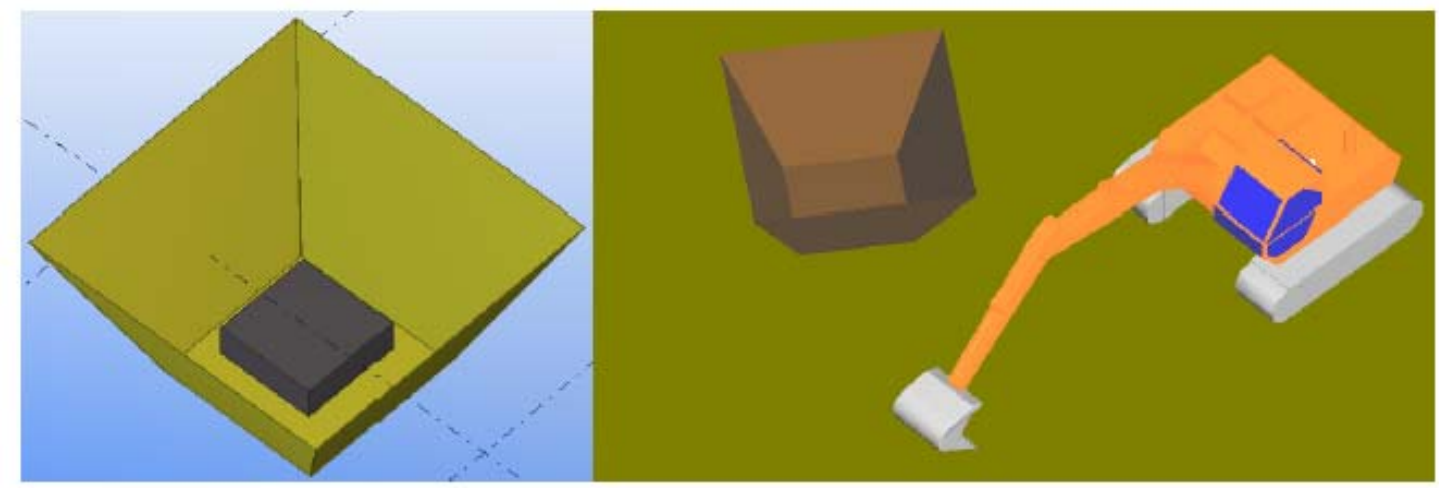

Figure 5. Foundation excavation model created with tool in Tekla Structures (left) and transferred to Novatron simulator (right). 
Also piles for the bridge foundations can be modelled in the bridge information model. A Finnish piling automation research project "POHVA2" has made tests with exporting pile data from Tekla Structures models directly to piling machine control system at building construction sites. This pile data transfer could also be applicable for bridge piling projects.

\section{CONCLUSIONS}

Designing bridges in 3D has been possible for several years now. For steel bridges the benefits are significant, as the process of design is straightforward. However most of the bridges designed in Finland today are steel reinforced concrete bridges that are cast on-site. This freeform type of construct with rebars inside poses a challenge for CAD softwares for modelling and blueprint production. These problems are currently being solved as several pilot concrete bridges, namely Cruselli-bridge in Helsinki, are being designed and built using information modelling.

In the near term future CAD software, design processes, administration procedures and dynamic 3d bridge component libraries are going to develop so that designing bridges in $3 \mathrm{~d}$ will be more cost effective than designing them in 2d. In addition bridge and road design softwares will be integrated so that they will better communicate together, enabling more efficient starts for bridge modelling projects. Ordering materials, such as rebar steels and cement to the construction site, will be done using data from the model. Construction sites will start relying on models to get their up to date information about the bridge project, and all surveying measurements will be stored in the model and will be available to all parties in real time. Machines working on the bridge site doing foundation work will also get data from the bridge information model.

National bridge modelling guidelines will speed the transition of the public administration and the private sector to 3D modelling. Overall, the transition to using 3D information models for bridge construction projects is clearly inevitable as more and more bridge projects are being designed via information modelling in Finland. Nearly every design consultant office is gearing for information modelling. Also general contractors are frantically working to develop their processes towards using data from information models and to reduce waste in construction work.

\section{REFERENCES}

Pulkkinen, P. \& Karjalainen, A. \& Heikkilä, R. (2008) 5D Bridge - Development of 5D Process and Tools for Bridge Engineering. IABSE (International Association for Bridge and Structural Engineering), Information and Communication Technology for Bridges, Buildings and Construction Practice, Helsinki, Finland, pp. 68-69.

Heikkilä, R. \& Pulkkinen, P. \& Karjalainen, A. \& Jaakkola, M. (2005) On the Economy and Benefits of 3-D Design Method in Bridge Engineering. ISARC'2005, The $22^{\text {nd }}$ International 
Symposium on Automation and Robotics in Construction, 11-14 September 2005, Ferrara, Italy, pp. 70-.

Heikkilä, R. \& Jaakkola, M. \& Pulkkinen, P. (2004) Modelling Measurements and Measuring Models - Problems and Solutions of 3-D Geometrical Control in Concrete Bridge Engineering. ISARC'2004, 21st International Symposium on Automation and Robotics in Construction, 21-25 September 2004. Jeju, Korea, pp. 81-84.

Heikkilä, R. \& Jaakkola, M. \& Pulkkinen, M. (2003) Connecting 3-D Concrete Bridge Design to 3-D Site Measurements. ISARC'2003, 20th International Symposium on Automation and Robotics in Construction, 21-24 September 2003. Eindhoven, the Netherlands, pp. 259-264.

Kivimäki, T. \& Heikkilä, R. (2009) Integrating 5D Product Modelling to On-site 3D Surveying of Bridges. ISARC'2009, The $26^{\text {th }}$ International Symposium on Automation and Robotics in Construction, 24-27 June 2009, Austin, Texas, U.S.A., pp. 445-450. 